\title{
Spontaneous Development of Hepatocellular Carcinoma and B-Cell Lymphoma in Mosaic and Heterozygous Brca2 and Cdkn1a Interacting Protein Knockout Mice
}

\author{
Huimei Lu, ${ }^{* \dagger}$ Caiyong Ye, ${ }^{* \dagger}$ Xing Feng, ${ }^{* \dagger}$ Jingmei Liu, ${ }^{* \dagger}$ Mantu Bhaumik, Bing Xia,${ }^{* \dagger}$ Chen Liu, ${ }^{\S}$ and Zhiyuan Shen ${ }^{* \dagger}$
}

From the Rutgers Cancer Institute of New Jersey* and the Departments of Radiation Oncology, ${ }^{\dagger}$ Pediatrics, ${ }^{\ddagger}$ and Pathology, ${ }^{\S}$ Rutgers Robert Wood Johnson Medical School, Rutgers, The State University of New Jersey, Piscataway, New Jersey

\author{
Accepted for publication \\ January 27, 2020. \\ Address correspondence to \\ Zhiyuan Shen, Ph.D., Rutgers \\ Cancer Institute of New Jersey, \\ Rutgers, The State University of \\ New Jersey, 195 Little Albany \\ St., New Brunswick, NJ \\ 08903. E-mail: shenzh@cinj. \\ rutgers.edu.
}

\begin{abstract}
Hepatocellular carcinoma (HCC) is the most common form of liver tumors. Although HCC is associated with chronic viral infections, alcoholic cirrhosis, and nonalcoholic fatty liver disease, genetic factors that contribute to the HCC risk remain unknown. The BRCA2 DNA repair associated (BRCA2) and cyclindependent kinase inhibitor $1 \mathrm{~A}$ (CDKN1A) interacting protein, known as BCCIP, are essential for cell viability and maintenance of genomic stability. In this study, we established a new genetically engineered mouse model with Bccip deficiency. Mosaic or heterozygous Bccip deletion conferred an increased risk of spontaneous liver tumorigenesis and B-cell lymphoma development at old age. These abnormalities are accompanied with chronic inflammation, histologic features of nonalcoholic steatohepatitis, keratin and ubiquitin aggregates within cytoplasmic Mallory-Denk bodies, and changes of the intracellular distribution of high-mobility group box 1 protein. Our study suggests BCCIP dysregulation as a risk factor for $\mathrm{HCC}$ and offers a novel mouse model for future investigations of nonviral or nonalcoholic causes of HCC development. (Am J Pathol 2020, 190: 1175-1187; https://doi.org/ 10.1016/j.ajpath.2020.01.020)
\end{abstract}

Liver cancer is one of the leading causes of cancer-related mortality. More than $70 \%$ of the liver cancers are histologically diagnosed as hepatocellular carcinoma (HCC). In addition to chronic viral infections and alcoholic cirrhosis, nonalcoholic fatty liver disease (NAFLD), including nonalcoholic steatohepatitis (NASH), obesity, and chronic liver inflammatory conditions, are also risk factors for HCC. ${ }^{1,2}$ The molecular origin and genetic factors of NASH and chronic inflammation-initiated HCC have not been fully understood, although dietary, liver toxins, and transgenic mouse models have been used to understand the development of NAFLD. ${ }^{3-7}$ A recent study found that reduction of the BRCA2 DNA repair associated (BRCA2) and cyclin-dependent kinase inhibitor $1 \mathrm{~A}(\mathrm{CDKN} 1 \mathrm{~A})$ interacting protein (BCCIP) expression is associated with poor prognosis of HCC. ${ }^{8}$ However, whether Bccip deficiency can directly cause liver cancer has not been tested.
BCCIP was originally identified as a BRCA2 and CNKN1A (p21) interacting protein. ${ }^{9,10}$ It suppresses spontaneous DNA damage, ${ }^{11-13}$ regulates RAD51 and p53 activity, ${ }^{14,15}$ facilitates $\mathrm{G} 1 / \mathrm{S}$ and mitotic cell cycle transitions, ${ }^{15-17}$ maintains centrosome and spindle fidelity, ${ }^{18}$ and regulates ribosomal proteins. ${ }^{19-21}$ BCCIP is also essential for the viability of organisms from fungus to mouse. $^{12,22,23}$ Likely because of its essential role in maintaining cell viability, germline and homozygous somatic $B C C I P$ mutations have rarely been reported in human cancers. However, BCCIP down-regulations have been observed in many cancer types, including kidney tumors, ${ }^{24}$

Supported by NIH grants R01CA156706 and R01CA195612 (Z.S.), a Robert Wood Johnson Foundation award, and Histopathology \& Imaging and Genome Editing Shared Resources of The Rutgers Cancer Institute of New Jersey grant P30CA072720.

Disclosures: None declared. 
gliomas, ${ }^{25}$ laryngeal cancers,${ }^{26}$ ovarian cancers,${ }^{27}$ colorectal cancers, ${ }^{27}$ breast cancers, ${ }^{28}$ and $\mathrm{HCC} .{ }^{8}$

The human BCCIP gene is located at chromosome 10q26.2. The $5^{\prime}$ end of the human BCCIP gene has a close head-to-head proximity with the UROS gene, and its $3^{\prime}$ end overlaps with the putative $D H X 32$ or $D D X 32$ gene in a tailto-tail fashion. ${ }^{24}$ Because the mouse Bccip is also close to the Uros and Dhx32 genes, previous studies have resorted to a transgenic conditional Bccip knockdown mouse line (LoxPshBCCIP), instead of a conventional knockout, to investigate the role of Bccip gene in mouse development and tumorigenesis. ${ }^{12,28-30}$ This mouse model has demonstrated that down-regulation of Bccip by RNA interference is sufficient to cause embryonic lethality. ${ }^{12}$ Furthermore, glial fibrillary acidic protein-Cre-mediated Bccip knockdown caused microcephaly and neurologic development defects, ${ }^{30}$ whereas K14-Cre-mediated Bccip knockdown resulted in the development of benign lesions in mammary glands. ${ }^{28}$ Interestingly, the neurodevelopmental defect of glial fibrillary acidic protein-Cre-mediated Bccip knockdown was rescued by co-deletion of $\operatorname{Tr} 553$, but this led to development of medulloblastomas. ${ }^{29}$ Although these studies have revealed the critical roles of Bccip in mouse development and tumorigenesis by Bccip down-regulation, models with complete Bccip loss have remained unavailable.

In the current study, we developed a new Bccip mouse model to further understand the role of Bccip in development and tumorigenesis. Homozygous deletion of Bccip caused embryonic lethality, but animals with mosaic and heterozygous Bccip deletion were viable. However, these mice had an increased risk of spontaneous liver tumorigenesis and B-cell lymphoma between 72 and 81 weeks of age. These pathologic findings are accompanied by a chronic inflammation pathologic finding, such as liver inflammation and necrosis, as well as with changes of highmobility group box 1 protein (HMGB1) intracellular distribution. An increased frequency of NASH-like histologic findings was also observed in the livers of Bccip-deficient mice compared with Bccip wild-type mice, including the appearance of ballooned hepatocytes and Mallory-Denk body-like cytoplasmic protein aggregates that contain keratin-18, keratin-8, and ubiquitin.

\section{Materials and Methods}

\section{Generation of a New Conditional Bccip Knockout Mouse Strain}

The animal works presented in this study were approved by the Institutional Animal Care and Use Committee at Rutgers Robert Johnson Medical School (IACUC I12-054). The study followed all institutional guidelines regarding animal welfare issues. All mice were fed with standard food supplied by the animal facility.

The strategy outlined in Supplemental Figure S1 was used to derive mouse embryo stem (ES) clones with floxed exon-5 of Bccip from a premade C57BL6N JM8 ES clone (HEPD 0517-2-E11, International Knockout Mouse Consortium, the European Conditional Mouse Mutagenesis Program) that had a trapped Bccip allele. The trapped ES clone was electroporated with $20 \mu \mathrm{g}$ of pCAGGS-FLPe-IRES-puro plasmid (Gene Bridge, Heidelberg, Germany) that transiently expresses flippase

Table 1 Primers Used for Genotyping for Mouse Embryo Stem Cell Cloning and Breeding

\begin{tabular}{|c|c|c|c|}
\hline Code & Primer name & Primer sequence & Primer location \\
\hline $\mathrm{X}$ & SCF & F: 5'-AAGGCGCATAACGATACCACG- $3^{\prime}$ & $\begin{array}{l}5^{\prime} \text { side of left FRT site (present in } \mathrm{KO} \text { vector but not in } \\
\text { WT genome) }\end{array}$ \\
\hline A1 & SCF1 & F: 5'-TGTCAGGGCAAGTGCTCCTTC-3' & $\begin{array}{l}\text { Intron 4, approximately } 132 \mathrm{bp} \text { from the end of } 5^{\prime} \text { arm, } \\
83 \mathrm{bp} \text { from SCF2 }\end{array}$ \\
\hline C & SCR & R: 5'-GAAGGTGGCCTGTGGCCTGCA C-3' & Intron $4,3^{\prime}$-side of 1 st LoxP site. \\
\hline B & K0-SCG R1 & R: 5'-GAACTAGGGGCAGTATTAAGG-3' & $\begin{array}{l}\text { Intron } 5,3^{\prime} \text { side from the end of the } 3^{\prime} \text { arm of the } \\
\text { targeting vector }\end{array}$ \\
\hline Y2 & K0-SCV R1 & R: 5'-CGACGAAGTTCCTATACTTTCTAG-3' & $\begin{array}{l}\text { Sequence from } \mathrm{KO} \text { vector, } 5^{\prime} \text { side of the first LoxP } \\
\text { (present in } \mathrm{KO} \text { vector but not in WT genome) }\end{array}$ \\
\hline \multirow[t]{2}{*}{ Gal2 } & Gal2F & F: 5'-ATCGTGCGGTGGTTGAACTGC- $3^{\prime}$ & Sequence present in trapped allele \\
\hline & Gal2R & R: 5'-CATCGGTCAGACGATTCATTG-3' & Sequence present in trapped allele \\
\hline
\end{tabular}

F, forward; FRT, flippase recombination; K0, knockout; R, reverse; WT, wild type. 
(FLP). The electroporation was conducted with 5 million ES cells in $700 \mathrm{~mL}$ of medium at $250 \mathrm{~V}, 250 \mathrm{mF}$. Then, the cells were incubated for 20 minutes at room temperature, diluted 500-fold, and plated into $10-\mathrm{cm}$ dishes. Eight days after culture, single clones were picked up and transferred into 96-well plates. After 4 days of culture, one 96-well plate was split into three plates: one plate for $\mathrm{X}$-gal staining, one for PCR genotyping, and one for culture expansion. The $\mathrm{X}$-gel-negative clones represent a potential success of $F L P$ recombination. The verifications of two correct ES clones were shown in Supplemental Figure S2. The primers for genotyping are listed in Table 1, and the expected product sizes are listed in Supplemental Table S1.

The D6 clone (Supplemental Figure S2) contained a wildtype allele and a LoxP-Bccip-exon5 conditional allele, which was then used for injection into Albino (white) blastocysts at the transgenic core facility and implanted into foster mice. A total of 6 chimeras ( 3 males and 3 females) were obtained. These male chimeras were bred with C57BL6 female mice, and germline transmission of mutated allele was screened by PCR with tail DNA from offspring. Among the first 80 offspring, two viable mice with germline transmissions were identified using the same PCR strategy as seen with the ES clone in Supplemental Figure S2. This produced the first generation of founder heterozygous conditional Bccip knockout mice, designated Bccip ${ }^{f / w t}$. In a parallel approach, the original Bccip-trapping clone
(Supplemental Figure S1) was directly used to generate chimera mice. Although two chimera mice were obtained, they failed to convey germline transmission, and subsequently this approach was abandoned. The first-generation founder mice were crossed to obtain heterozygous and homozygous LoxP-Bccip-Exon 5 mice, Bccip ${ }^{f / w t}$ and Bccip ${ }^{f / f}$. The genotyping of the mice was conducted according to the PCR strategy outlined in Supplemental Figure S2 and Supplemental Table S2. To verify whether the conditional allele in the mice is susceptible for Bccip-exon 5 deletion on expression of Cre-recombinase, the mouse embryo fibroblasts were established from the conditional mice using previously reported procedures. ${ }^{12}$ The newly generated conditional mice with the floxed Bccip allele, designated $B c c i p^{f / w t}$, were crossed with each other to generate Bccip ${ }^{f / f}$ mice. Effective recombination between the LoxP sequences to delete Bccip exon 5 and subsequent Bccip mRNA truncation and loss of Bccip protein were verified and described in Supplemental Figure S3. Then, the Bccip ${ }^{f / w t}$ mice were crossed with EIIa-Cre ${ }^{+/+}$mice (Jackson Laboratory, Bar Harbor, ME) to generate $\mathrm{Bccip}^{\Delta E x 5 / w t} ; \mathrm{EIIa}^{-\mathrm{Cr}^{+/-}}$mice, which were then used to cross with $B c c i p^{\text {fff }}$ mice to generate

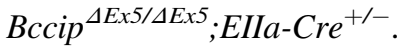

As described previously, ${ }^{12,29,30}$ the mouse Bccip is in close to two neighboring genes: Uros and Dhx32 or Ddx32. There was initially a concern about whether deletion of Bccip may affect these neighboring genes. To address this, RT-PCR was used to assess the expression of the Bccip,
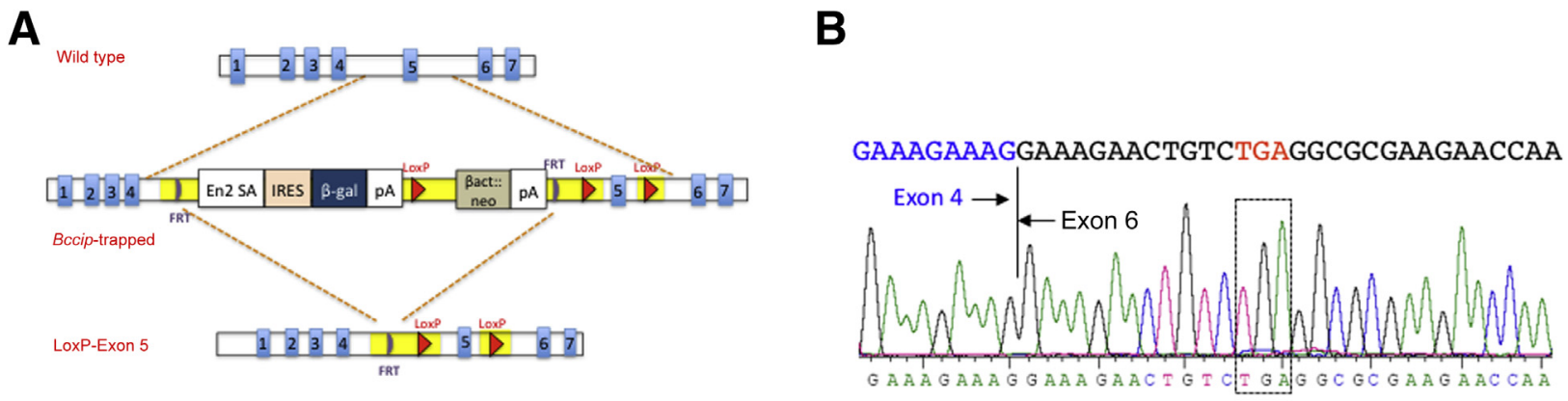

$\Delta$ Exon 5

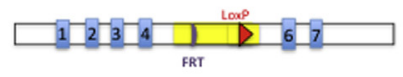

C

$\begin{array}{lllllllll}1 & 2 & 3 & 4 & 5 & 6 & 7 & 8 & 9\end{array}$

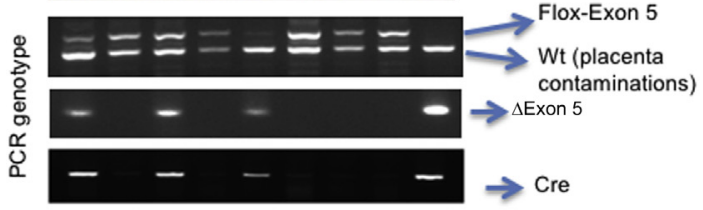

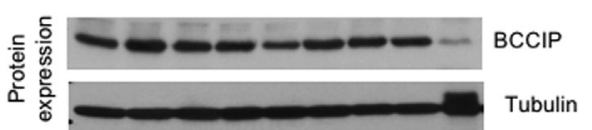

Figure 1 Genomic structure of the engineered Brca2 DNA repair associated (Brca2) and cyclin-dependent kinase inhibitor $1 \mathrm{~A}$ (Cdkn1a) interacting protein (Bccip) alleles and lethality of homozygous Bccip-null embryos. A: Diagrams of four different mouse Bccip alleles. Shown is the endogenous wild-type allele (top panel), the trapped allele contained in an embryo stem clone obtained from International Knockout Mouse Consortium and the European Conditional Mouse Mutagenesis Program, the exon 5 floxed allele, and the Bccip$\triangle E x o n 5$ allele. $L o x P$ is the Cre-recombination site. Bottom panel shows a $\triangle E x o n 5$ allele. B: Sequencing chronograph of Bccip- $\triangle$ Exon 5 mRNA. Arrows indicate the junction between exon 4 and exon 6 . The predicted reading frame shift that causes a premature stop codon is shown in red. Boxed area represents the new stop codon. C: The embryo morphologic features, genotypes, and their Bccip protein levels of a representative litter. Embryos 1, 3, 5, and 9 were Cre-positive. Embryos 1, 3, and 5 have incomplete Cre-mediated LoxP recombination, but embryo 9 has completely lost the floxed exon 5 allele. Western blot confirmed that embryo 9 lost the Bccip protein, but all other embryos have relatively normal level of Bccip protein. FRT, flippase recombination; Wt, wild-type. 
Table 2 Genotype Distribution of Newborns from Cross-Breeding between Bccip ${ }^{\Delta E x 5 / w t} ; E I I a-C r e^{+/-}$and Bccip ${ }^{f / f}$

\begin{tabular}{|c|c|c|c|c|}
\hline Bccip status & Offspring genotype & Pups, $n$ & Expected, \% & Actual, \% \\
\hline $\mathrm{Bccip}^{+/+}$ & Bccip $^{f / w t} ; E I I a C r e^{-/-}$ & 49 & 25 & 29.7 \\
\hline $\mathrm{Bccip}^{+/-}$ & Bccip $^{\Delta E \times 5 / f} ;$ EIIaCre $^{-/-}$ & 50 & 25 & 30.9 \\
\hline Bccip $^{+/-}$ & Bccip $^{\Delta E \times 5 / w t} ;$ EIIaCre $^{+/-}$ & 48 & 25 & 29.1 \\
\hline Bccip $^{-/-}$and mosaic & Bccip $^{\Delta E \times 5 / \Delta E \times 5} ; E I I a C r e^{+/-}$ & 0 & 25 & 10.9 \\
\hline Bccip deletion & Bccip $^{\Delta E \times 5 / f: \Delta E \times 5} ; E I I a C r e^{+/-*}$ & 18 & & \\
\hline
\end{tabular}

Bccip, Brca2 DNA repair associated (Brca2) and cyclin-dependent kinase inhibitor 1A (Cdkn1a) interacting protein.

${ }^{*} B c c i p^{\Delta E \times 5 / f: \Delta E \times 5} ;$ EIIaCre ${ }^{+/-}$: mosaic mice containing one allele of floxed Bccip that failed to complete Cre-mediated recombination.

Uros, and Dhx32 genes, and the results are shown in Supplemental Figure S4. Uros primers were $5^{\prime}$ ATGAAGGTTCTCTTACTAAAAG- $3^{\prime}$ (forward) and $5^{\prime}$ CGCTCCTTCTGCATCCAGACC-3' (reverse). Dhx32 primers were $5^{\prime}$-AAAGCGCTGCTCTCTGGGTAC-3 ${ }^{\prime}$ (forward) and 5'-TCACTGGATTGTGCATCTCTG-3' (reverse). Bccip primers were 5'-CAAACAGATGTTTCAGAAGAC-3' (forward) and 5'-CTCATAGAAGAACTCTTCCTC-3' (reverse).

\section{Antibodies, Western Blotting, and Immunostaining}

The anti-BCCIP antibody has been previously characterized. $^{12,18,29,30}$ Commercial antibodies are as follows: CD45R/B220 [1:200 for immunohistochemistry (IHC); Biolegend, San Diego, CA] and CD34 (1:100 for IHC; Biolegend), anti-human CD3 (1:200 for IHC; Dako, Glostrup, Denmark), HMGB1 (1:100 for immunofluorescence and IHC, 1:1000 for Western blot; Cell Signaling Technology, Danvers, MA), tubulin (1:2000), anti-Ki-67 (1:500 for IHC; Abcam, Cambridge, MA), glypican-3 (1:100; Santa Cruz Biotechnology, Santa Cruz, Dallas, TX). Polyclonal anti-p62 (1:200 for IHC, 1:2000 for Western blot; Enzo Life Sciences, Farmingdale, NY), cytokeratin-8 (C-51, 1:100, Santa Cruz Biotechnology), cytokeratin-18 (C-04, 1:100; Santa Cruz Biotechnology), and anti-polyubiquitin chain monoclonal antibody (clone FK2, 1:200; Biomol International, Plymouth Meeting, PA).

\section{Histological Analysis and IHC}

Tissues were dissected from mice, rinsed with phosphatebuffered saline, fixed in $10 \%$ neutral buffered formalin overnight at $4^{\circ} \mathrm{C}$, and then transferred to $70 \%$ ethanol. The fixed tissues were used to make paraffin-embedded blocks at the Rutgers Cancer Institute of New Jersey Core Facility. Tissue sections of $5 \mu \mathrm{m}$ were cut and stained with hematoxylin and eosin (H\&E) according to a previously developed protocol. ${ }^{12,30}$ For IHC, the dried slides (in $50^{\circ} \mathrm{C}$ incubator overnight) were deparaffinized in xylene, rehydrated in $100 \%, 90 \%$, and $70 \%$ ethanol, and rinsed in running tap water for 5 minutes. To retrieve the antigen, a container filled with retrieval buffer (10 $\mathrm{mol} / \mathrm{L}$ sodium citrate, $\mathrm{pH}$ 6.0) was boiled in a rice cooker, and then the slides were transferred into the boiling retrieval buffer and steamed for 25 minutes. The cooled-down slides were washed in Tris-Buffered Saline with $0.1 \%$ Tween 20 detergent (TBS-T) three times for 5 minutes each. Slides were immersed in $1 \%$ hydrogen peroxide in methanol for 20 minutes, washed in TBS-T three time for 5 minutes each, and blocked in TBS-T with $5 \%$ normal serum for 1 hour at room temperature to block endogenous peroxidase. Antibodies and dilution factors listed above were used for IHC staining. The primary antibodies were diluted in TBS-T with $1 \%$ bovine serum albumin. Slides were incubated with primary antibodies overnight at $4^{\circ} \mathrm{C}$, rinsed three times for 5 minutes each in TBS-T with gentle agitation, and then incubated in diluted horseradish peroxidase second antibodies for 1 hour at room temperature or with Vectastain ABC kit (Vector Laboratories Inc, Burlingame, CA) according to the instructions. Slides were developed with 3,3diaminobenzidine tetrahydrochloride hydrate diaminobenzidine (Sigma Chemical Co, St Louis, MO), counterstained with hematoxylin, dehydrated, cleared, and mounted.

\section{Soluble and Insoluble Protein Extraction and Western Blot}

A modified protocol was used to isolate the soluble and insoluble proteins from tissue samples. ${ }^{31,32}$ Briefly, the

Table 3 Gross Abnormalities in Brca2 and Bccip Wild-Type and Bccip-Deficient Mice

\begin{tabular}{llllll}
\hline Bccip status & $\begin{array}{l}\text { Total } \\
\text { mice, } n\end{array}$ & $\begin{array}{l}\text { Lymphoma, } \\
n(\%)\end{array}$ & $\begin{array}{l}\text { Mice with liver } \\
\text { tumors, } n(\%)\end{array}$ & $\begin{array}{l}\text { Mice with liver inflammation } \\
\text { and necrosis, } n(\%)\end{array}$ & $\begin{array}{l}\text { Mice with enlarged } \\
\text { spleens, } n(\%)\end{array}$ \\
\hline Bccip $+/+$ & 17 & 0 & 0 & 0 & $1(5.8)$ \\
Bccip-deficient mice & 44 & $9(20.5)$ & $3(6.8)$ & $5(11.4)$ & $12(27.3)$ \\
Bccip $+/-$ & 34 & 7 & 1 & 3 & 7 \\
Bccip-/- and Bccip $+/{ }^{*}$ & 10 & 2 & 2 & 2 & 5 \\
\hline
\end{tabular}

*Mosaic of $B c c i p(\Delta E \times 5 / L o x P)$ and Bccip $(\Delta E \times 5 / \Delta E \times 5)$; Cre (+/-). 


\section{A Representative large lymphoma mass}
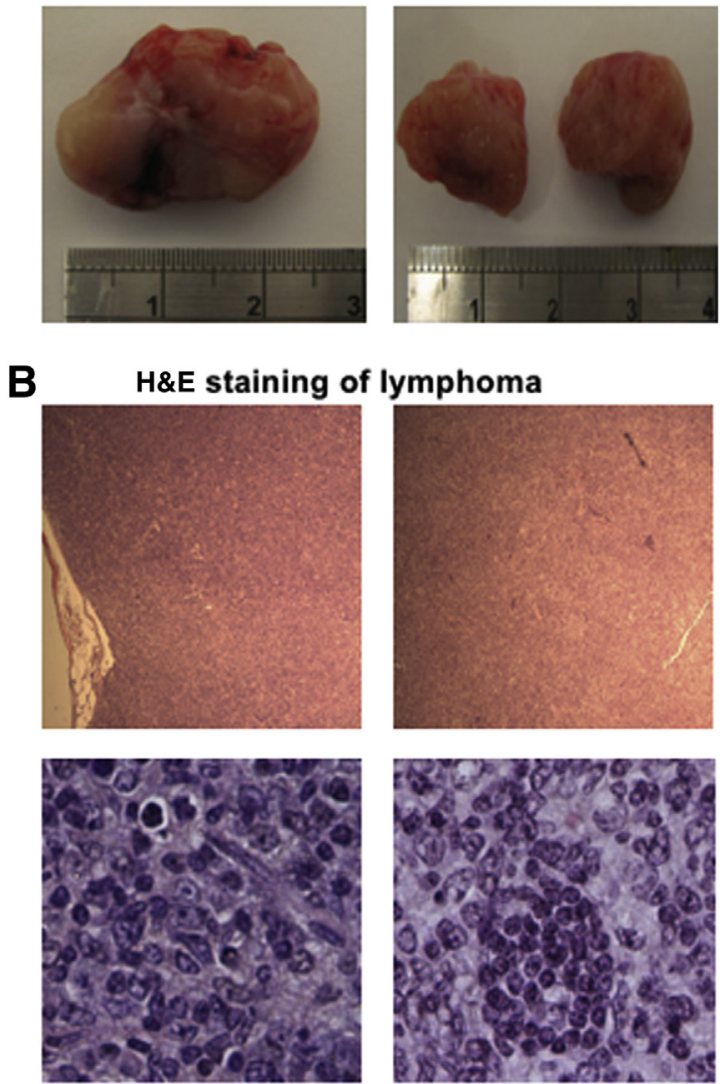

Mosaic BCCIP(-/-) and (+/-)

C
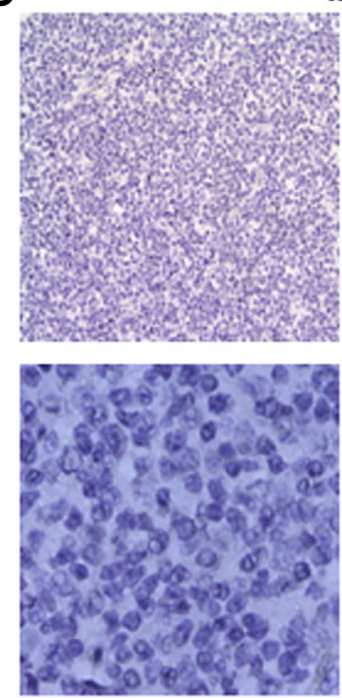

CD3 (T-cell marker)
IHC
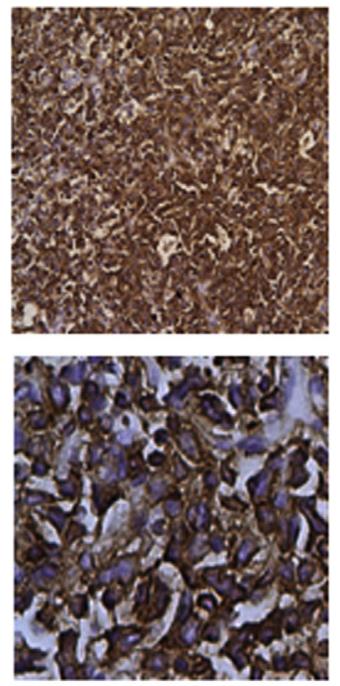

CD45R/B229 (B-cell marker)

Figure 2 Histopathologic characterization of lymphoma developed in Brca2 DNA repair associated (Brca2) and cyclin-dependent kinase inhibitor $1 \mathrm{~A}$ (Cdkn1a) interacting protein (Bccip)-deficient mouse. A: Representative lymphoma masses. B: Representative hematoxylin and eosin (H\&E) staining of lymphomas in Bccip mosaic (left) and Bccip heterozygous deletion (right) mice. C: Representative immunohistochemical (IHC) staining for lymphoma markers CD3 ( $T$ cells) and CD45R/B220 (B cells). Original magnification: $\times 4$ (B, top row); $\times 40$ (B and $C$, bottom rows); $\times 10$ (C, top row).

samples were first homogenized in $200 \mu \mathrm{L}$ of lysis buffer (50 mol/L HEPES, $\mathrm{pH} 7.4,150 \mathrm{~mol} / \mathrm{L}$ sodium chloride, $1 \%$ NP-40, $0.5 \%$ sodium deoxycholate, $0.1 \%$ SDS) containing protease inhibitors on ice and then centrifuged at $17,000 \times g, 4^{\circ} \mathrm{C}$ for 10 minutes. The supernatants were collected and saved as the soluble fractions. The pellets were washed once with another $200-\mu \mathrm{L}$ lysis buffer and centrifuged for 2 minutes, the supernatants were discarded, and then the pellets were resuspended in $200 \mu \mathrm{L}$ of a buffer that contained $60 \mathrm{~mol} / \mathrm{L}$ Tris hydrochloride, 2\% SDS, and 2.5\% 2-mercapthoethanl and proteinase inhibitors. The sample was sonicated for 1 minute three times, incubated on ice for another $20 \mathrm{mi}-$ nutes, and centrifuged at $17,000 \times g$ at $4^{\circ} \mathrm{C}$ for $10 \mathrm{mi}-$ nutes, and then the supernatants were collected as the insoluble fractions. The amount of proteins was quantified with Bio-Rad DC protein assay kit (Bio-Rad Laboratories, Hercules, CA). Equivalent amount of proteins from both soluble and insoluble fractions $(20 \mu \mathrm{g})$ were used to load onto $10 \%$ SDS-PAGE gel and blotted onto nitrocellulose membrane.

\section{HMGB1 Analysis in BCCIP Knockdown Cells}

Methods of cell culture and retrovirus infection and establishment of mouse embryo fibroblasts have been previously reported. ${ }^{12,18}$ Previously described BCCIP siRNA and Lenti-viral shRNA ${ }^{18}$ were used to knockdown human $B C C I P$ in cultured cells. Twenty-four hours after transfection, human skin fibroblast cells were treated with $3 \mathrm{ng} / \mathrm{mL}$ of IL- $1 \beta$ in $\alpha$-minimum essential medium for 24 hours and then stained for HMGB1. At the same time, a set of the same cells were collected to isolate nuclear and cytoplasmic proteins according to a previous report, ${ }^{33}$ with some modifications. Briefly, $1 \times 10^{6}$ of cells were lyzed in $50 \mu \mathrm{L}$ of permeabilization buffer $(10 \mathrm{~mol} / \mathrm{L}$ HEPES, $\mathrm{pH}$ $7.4,10 \mathrm{~mol} / \mathrm{L}$ potassium, $0.05 \% \mathrm{NP}-40$, and protease inhibitors) on ice for 10 minutes and centrifuged at $1600 \times g$ at $4^{\circ} \mathrm{C}$ for 5 minutes. The supernatants were collected and saved as the cytoplasmic fractions. The pellets were washed once with $200 \mu \mathrm{L}$ of permeabilization buffer and centrifuged for 2 minutes. After the supernatant was discarded, the pellets were resuspended in $25 \mu \mathrm{L}$ of $0.2 \mathrm{~N}$ hydrochloride, incubated on ice for 10 minutes, and centrifuged at $13,000 \mathrm{rpm}$ for 10 minutes at $4{ }^{\circ} \mathrm{C}$, and then the supernatants were collected and neutralized with $25 \mu \mathrm{L}$

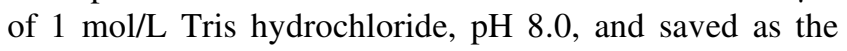
nuclear fractions.

\section{Statistical Analysis}

Statistical differences were determined with the $t$-test and $\chi^{2}$ test. $P<0.05$ was considered to be statistically significant. 


\section{Results}

\section{Generation of a New Mouse Model with Floxed Bccip Exon 5}

To develop a system that can completely inactivate mouse Bccip, a mouse ES clone with a single allele of trapped Bccip (Supplemental Figure S1) was used, which can lead to a floxed allele of Bccip exon 5. Exon 5 is located at the middle of the Bccip gene locus and does not overlap with either of the neighboring Uros and Dhx32 genes. This clone was used as a starting point, successfully generated mouse
ES clones with floxed Bccip exon 5, and then established founder mice with the same genomic locus. Details of the construction of ES clones and the floxed Bccip allele are given in Supplemental Figures S1 and S2 and outlined in Figure 1A. Briefly, the FLP recombinase was transiently expressed in the ES cells with a trapped allele of Bccip, and subclones with verified FLP recombination were isolated. After the karyotypes of the subclones were verified by metaphase spread analysis, one of the clones with floxed exon 5 of Bccip was used to generate chimeras, which were subsequently used to generate germline-transmitted, heterozygous founder mice, designated $B c c i p^{f / w t}$. These mice
A
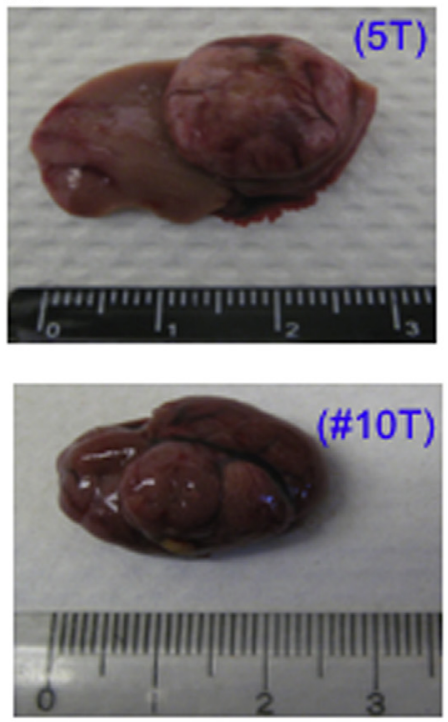

C
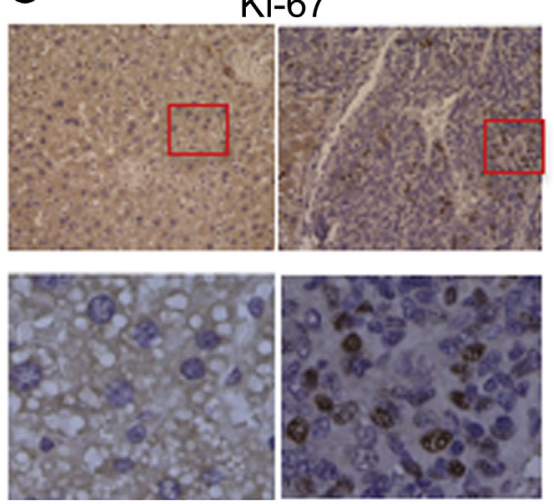

Nontumor region

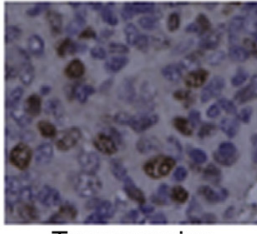

Tumor region
B
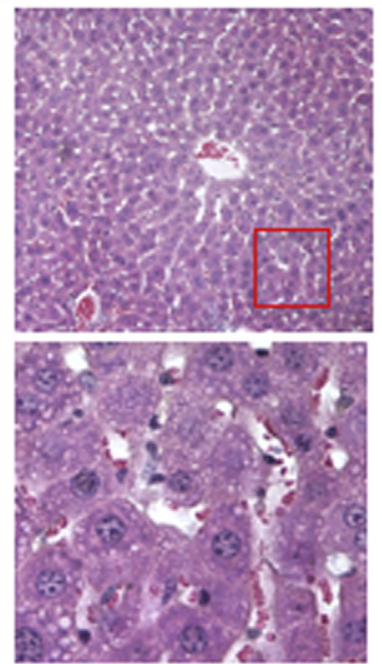

WT mouse (nontumor tissue)
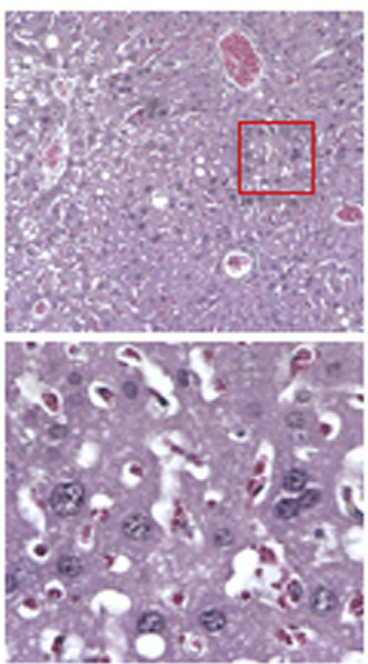

Bccip mosaic mouse (tumor tissue)
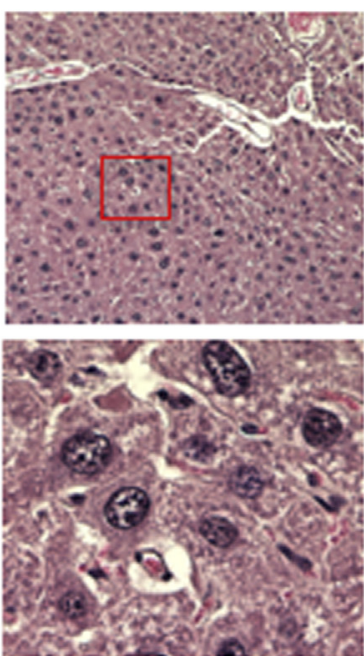

Bccip+/- mouse (tumor tissue)
D
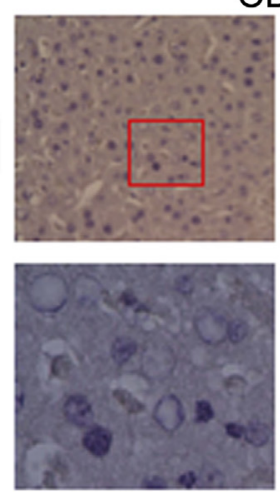

Nontumor region
CD34
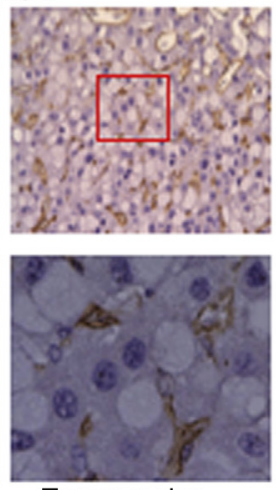

Tumor region
$\mathbf{E}$
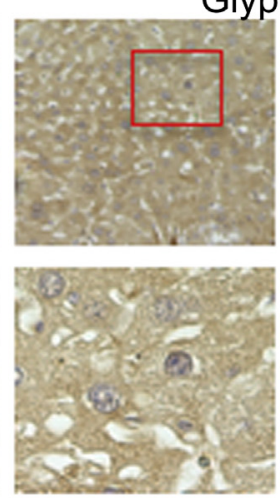

Nontumor region
Glypican 3
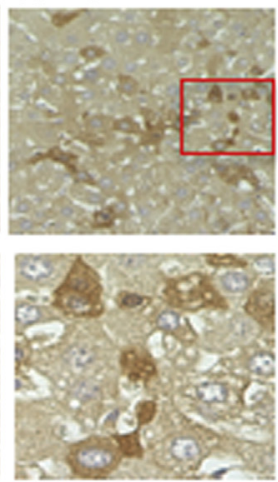

Tumor region

Figure 3 Pathologic characterization of liver tumors formed in mosaic and heterozygous Brca2 DNA repair associated (Brca2) and cyclin-dependent kinase inhibitor 1A (Cdkn1a) interacting protein (Bccip)-deficient mice. A: Representative livers with tumor mass obtained from a Bccip mosaic (top) and heterozygous (bottom) mice. B: Representative hematoxylin and eosin for morphology of normal liver tissues (left column), Bccip mosaic tumor tissues (middle column), and Bccip heterozygous tumor tissues (right column). C-E: Representative immunohistochemistry for proliferation marker Ki-67 (C), CD34 [a hepatocellular carcinoma (HCC) marker of the endothelial cells in the sinusoidal space] (D), and glypican 3 (an HCC marker in tumor cells) (E) in the tumor and non-tumor regions. Boxed areas are shown at higher magnification in the bottom rows $(\mathbf{B}-\mathbf{E})$. Original magnification: $\times 10(\mathbf{B}-\mathbf{E}$, top rows); $\times 40(\mathbf{B}-\mathbf{E}$, bottom rows). 
were fertile and successfully produced homozygous conditional Bccip mice, designated Bccip $^{f / f}$. It was verified that the deletion of exon 5 caused the skipping of the exon 5 in the Bccip mRNA, resulting in a frame shift (Figure 1B) and the loss of BCCIP protein (Supplemental Figure S3), and that it did not affect the expression of the neighboring Uros and Dhx32 genes (Supplemental Figure S4). Thus, a new mouse line with a floxed Bccip exon 5 was successfully established and verified. For simplicity, the symbols $B c c i p^{w t / w t}, B c c i p^{f / w t}$, and $B c c i p^{f f f}$ will be used in the rest of the report to refer the wild-type, heterozygous, and homozygous Bccip conditional mice, respectively. $B c c i p^{\Delta E x 5 / w t}$ refers to mouse with confirmed single-copy Bccip exon 5 deletion.

\section{EIIa-Cre-Mediated Bccip Exon 5 Deletion Causes}

Embryonic Lethality, but Mice with Mosaic, Incomplete Bccip Exon 5 Deletion Are Viable

To generate Bccip knockout mice, $B c c i p^{f / w t}$ was first crossed with EIIa-Cre $e^{+/+}$transgenic mice to produce the Bccip ${ }^{\Delta E x 5 / w t}$; EIIa-Cre $e^{+/-}$pups, which were then crossed with Bccip ${ }^{\text {fif }}$ mice. The genotype distribution of the pups is detailed in Table 2. Although the theoretical distribution among the Bccip $^{\Delta E x 5 / \Delta E x 5} ;$ EIIa-Cre $^{+/-}, \quad$ Bccip ${ }^{\Delta E x 5 / f} ;$ EIIa-Cre $^{-/-}$,

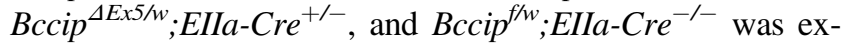
pected to be $1: 1: 1: 1$, this study failed to obtain live pups with the $\mathrm{Bccip}^{\Delta E x 5 / \Delta E x 5}$;EIIa-Cre $e^{+/-}$genotype, suggesting that the Bccip ${ }^{\Delta E x 5 / \Delta E x 5} ; E I I a-C r e^{+/-}$genotype is embryonic lethal. Interestingly, $11 \%$ of pups were observed with the $\mathrm{Bccip}^{\Delta \mathrm{Ex} 5 / f} ; \mathrm{EIIa-Cre} \mathrm{C}^{+/-}$genotype, indicating an incomplete EIIa-Cre-mediated recombination at the floxed exon 5, which leads to mosaic offspring with $B c c i p^{\Delta E x 5 / f} ;$ EIIa$\mathrm{Cre}^{+/-}$and possibly Bccip ${ }^{\Delta E x 5 / \Delta E x 5} ;$ EIIa-Cre ${ }^{+/-}$genotypes. Because the mean number of pups of the three viable genotype is 49 (Table 2), the estimated portion of viable Bccip $^{f f f}$;EIIa-Cre $e^{+/-}$mice that underwent mosaic Bccip deletion is estimated at roughly one-third (18 of 49), and thus approximately two-thirds of $\mathrm{Bccip}^{\mathrm{fff}} ; \mathrm{EIIa}_{\mathrm{Cr}} \mathrm{Cr}^{+/-}$mice may have died embryonically because of complete deletion of exon 5. Genotyping and Western blotting analyses confirmed that embryos with $B c c i p^{\Delta E x 5}$ were inviable (Figure 1C), which is similar to the previously reported embryonic lethality of conditional Bccip knockdown using EIIa-Cre. ${ }^{12}$
A

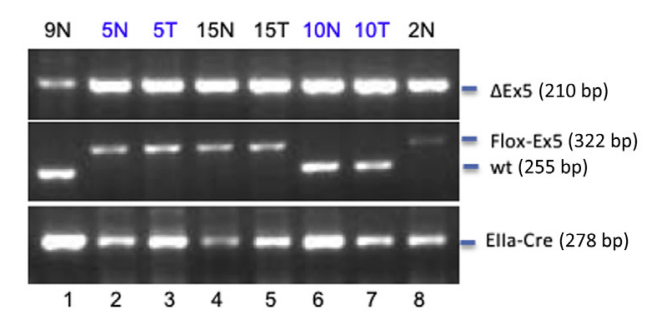

C
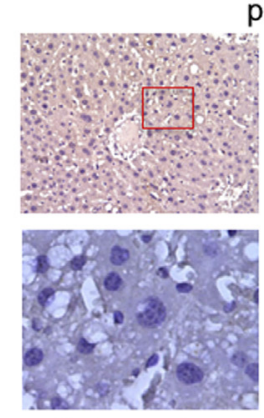

Nontumor region p62
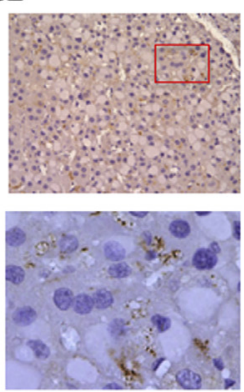

Tumor region
B

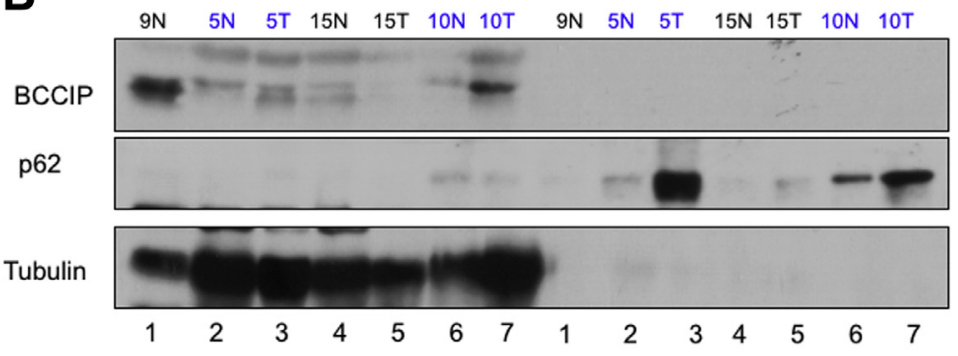

D

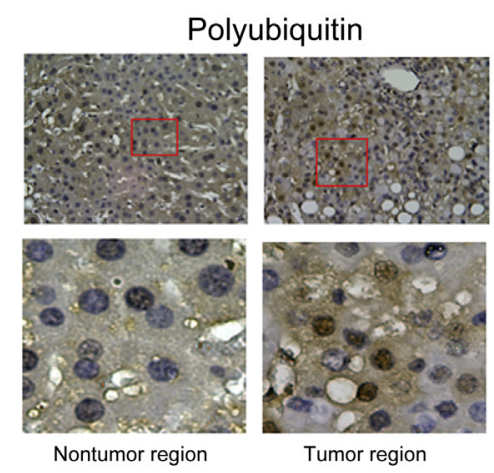

Figure 4 Verification of liver tumors originated from Brca2 DNA repair associated (Brca2) and cyclin-dependent kinase inhibitor 1A (Cdkn1a) interacting protein (Bccip)-deficient cells. A: PCR genotype to confirm the Bccip mosaic and heterozygous status in three liver tumor tissues. The specific tissue type and genotype of the mice are as follows: lane 1: $9 \mathrm{~N}, B c c i p(\Delta E \times 5 / w t) ; C r e+/-$, normal tissue, heterozygous; lane 2: $5 \mathrm{~N}, B c c i p(\Delta E x 5 / f l o x)$; $C r e+/-$, normal tissue adjacent to tumor, mosaic; lane 3: 5T, Bccip ( $\Delta E x 5 / f l o x)$; Cre+/-, liver tumor tissue, mosaic; lane 4: $15 \mathrm{~N}, B c c i p(\Delta E x 5 / f l o x)$; Cre+/-, normal tissue adjacent to tumor, mosaic; lane 5: 15T, Bccip $(\Delta E x 5 / f l o x)$; $C r e+/-$, tumor tissue, mosaic; lane 6: $10 \mathrm{~N}, B c c i p(\Delta E x 5 / w t)$; Cre+/-, normal tissue adjacent to tumor, heterozygous; lane 7: 10T, Bccip ( $\Delta E x 5 / w t)$; Cre+/-, tumor tissue, heterozygous; lane 8: 2N, Bccip( $\Delta E x 5 / f l o x)$; Cre+/-, normal tissue, mosaic. B: Bccip and p62 protein levels in the tissue extracts. Soluble and insoluble proteins were extracted from three liver tumor and normal tissues. Anti-Bccip and anti-p62 Western blot were performed to measure Bccip and p62 levels in these tissues as described in A. Reblot with antitubulin was used as a loading reference. C: Immunohistochemistry (IHC) for p62 in liver tumor tissue (right column) and adjacent nontumor tissue (left column). D: IHC for polyubiquitin in liver tumor tissue (right column) and adjacent nontumor tissue (left column). Blue and black text shows the paired normal and tissue from the same mouse or to contrast the genotypes. Boxed areas are shown at higher magnification in the bottom row (C and D). Original magnification: $\times 10$ (C and $\mathbf{D}$, top rows); $\times 40$ (C and $\mathbf{D}$, bottom rows). 
Mice with Heterozygous and Mosaic Bccip Deletions Are Prone to Spontaneous Lymphoma and Liver Cancer Development

To assess the long-term consequence of Bccip deficiency in mouse development and tumorigenesis, some of the viable mice in Table 2 were used for lifetime observation. The main observations from 44 Bccip-deficient mice and 17 wild-type mice are detailed in Supplemental Table S2. The appearances and behaviors of partial Bccip-deficient mice were largely normal during the observed period. However, on dissection of the mice at approximately 18 months, abnormalities in the livers and spleens and presence of lymphoma masses were observed. As summarized in Table 3 and detailed in Supplemental Table S2, among the 34 mice with heterozygous Bccip deletion $\left(\right.$ Bccip $^{\Delta E x 5 / w t} ;$ EIIa-Cre $^{+/-}$ and $\mathrm{Bccip}^{\Delta E \times 5 / f} ; \mathrm{EIIa}_{\mathrm{C}} \mathrm{Cre}^{-/-}$) and the 10 mice with mosaic Bccip deletions, nine developed lymphoma and three developed liver tumors. The overall tumor burden of the Bccip-deficient mice was 12 of 44 but for Bccip-proficient mice was 0 of 17 , and this difference is statistically significant $(P=0.016)$. These observations strongly suggest that Bccip defects confer an increased risk of spontaneous tumor development in the animals.

All lymphoma masses were observed in the abdomen, including large lymphomas adjacent to the mesentery (Figure 2A) and others adjacent to pancreases, fat pad, or abdomen wall. H\&E staining of the lymphomas revealed that most cells were lymphocytes (Figure 2B). All nine cases analyzed tested negative for CD3 (T-cell marker) but positive for CD45R/B220 (B-cell lymphoma marker) (Figure 2C). Therefore, the Bccip defects conferred an increased risk of B-cell lymphoma.

Large liver tumor masses were found in three Bccipdeficient mice, and they all had defined boundaries (Figure 3A). H\&E staining revealed loss of normal liver architecture, such as basic liver lobules with portal areas. Large nucleoli and irregular nuclear contours were notable (Figure 3B). The tumor regions had more Ki-67-positive cells than the nontumor region (Figure $3 \mathrm{C}$ ). In addition, all tumor tissues were CD34 positive in the sinusoidal spaces aligned with endothelial cells (Figure 3D). The liver tumor cells displayed strong glypican-3 staining in the cytoplasm and membrane compared with adjacent nontumor tissue (Figure 3E). The combined positive staining of glypican-3 and CD34 is generally considered a reliable biomarker of HCC. ${ }^{34-36}$ DNA analysis confirmed that both tumor and nontumor tissues of the same mice had the anticipated Bccip deletion (Figure 4A). Bccip protein levels in the mosaic tumors were reduced when compared with the normal liver tissues of heterozygous mice (Figure 4B). These data confirm that the liver tumors indeed originated from the Bccip-deficient cells. Interestingly, in two of the three analyzed liver tumor tissues, accumulated insoluble p62 (Figure 4, B and C) and elevated levels of polyubiquitinated proteins were noted (Figure 4D). No obvious changes of microtubule-associated protein 1A/1B-light chain 3 (LC3) were observed in the tumor tissue (data not shown). Terminal deoxynucleotidyl transferase-mediated dUTP nickend labeling assays did not reveal any significant apoptosis in the tumor sections. These observations indicate an accumulation of misfolded proteins.

In some liver tissues, hepatocytes had disappeared in certain areas, and instead many immune cells, such as mononuclear cells, had invaded these areas (Figure 5A). Two of these Bccip-deficient mice (but none of the 17 Bccip $^{f / \omega t} ; E I I a-C r e^{-/-}$mice) had a pale appearance at the edge of the livers, but no tumor masses were observed. Histologically, the cell morphologic features still resembled those of a normal hepatocyte, but the nucleus had shrunk and vesicular structures had developed in the cytoplasm (Figure 5, B and C). Therefore, additional nontumor liver tissues were examined more in details, including 8 from wildtype and 17 ( 8 male and 11 female) from Bccip-deficient mice
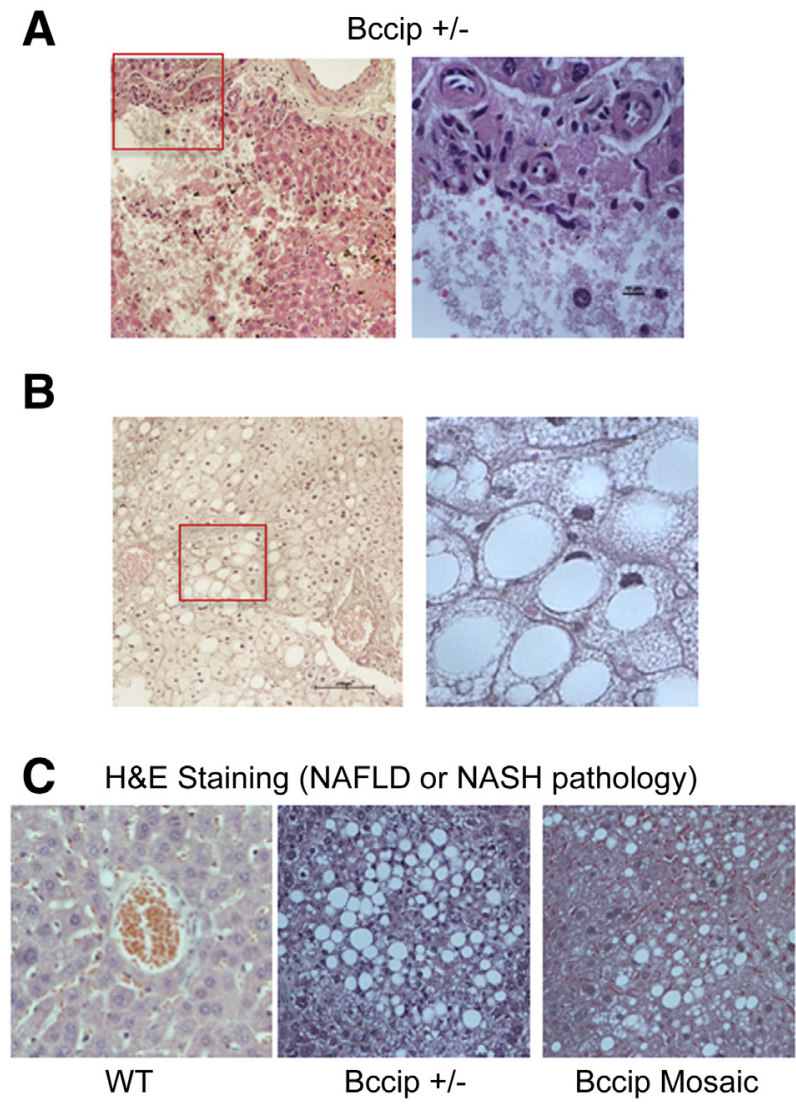

Figure 5 Inflammation and nonalcoholic steatohepatitis (NASH)-like pathologic features in the Brca2 DNA repair associated (Brca2) and cyclindependent kinase inhibitor $1 \mathrm{~A}$ (Cdkn1a) interacting protein (Bccip)-deficient livers. A: Representative images for inflammatory regions in liver tissues of the Bccip+/- mice. B: A representative area of Bccip-deficient liver with vascular cytoplasm structure. Boxed areas are shown at higher magnification in the right panels ( $\mathbf{A}$ and $\mathbf{B})$. C: Representative hemotoxylin and eosin (H\&E) images of ballooning hepatocytes of NASH-like histologic features in Bccip heterozygous mouse and mosaic mouse. Original magnification: $\times 10$ (A and B, left panels, and $\mathbf{C}) ; \times 40$ (A, and B, right panels). NAFLD, nonalcoholic fatty liver disease; WT, wild type. 


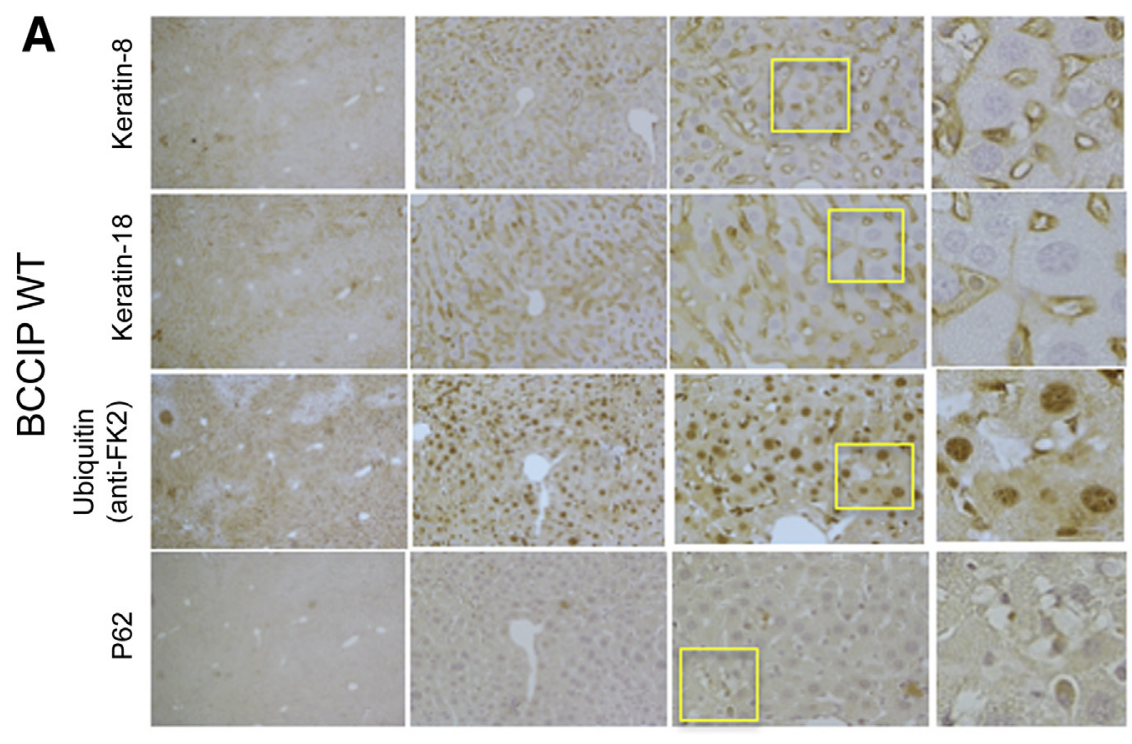

B
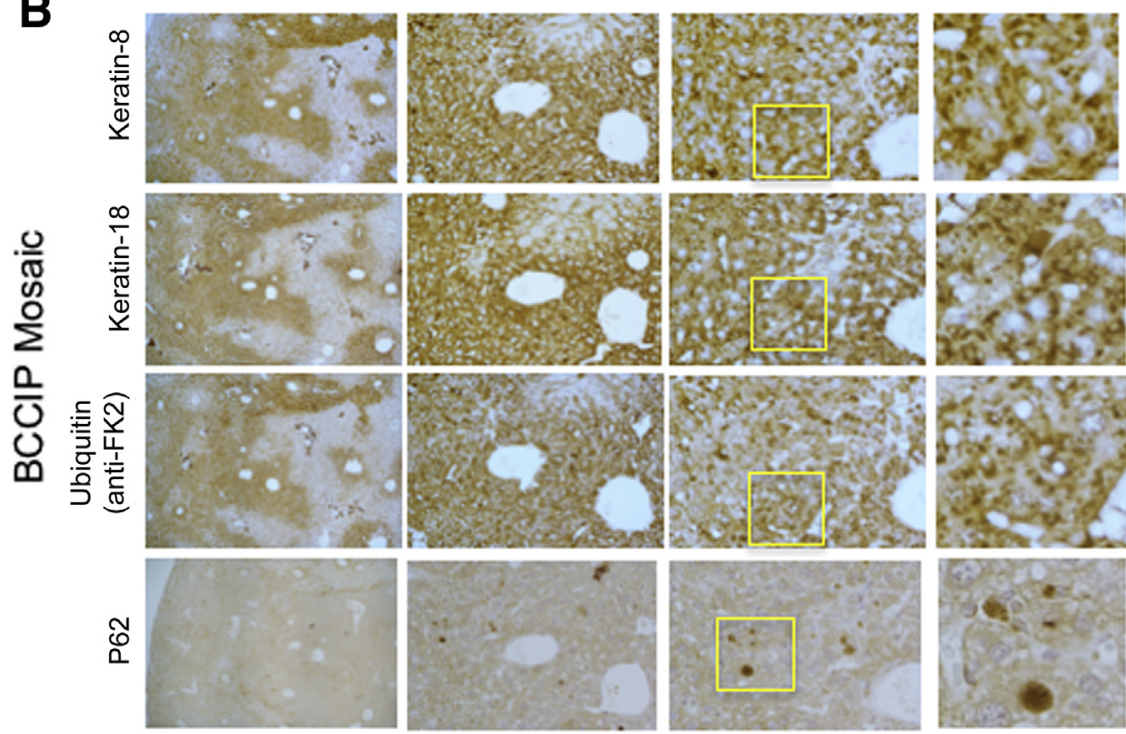

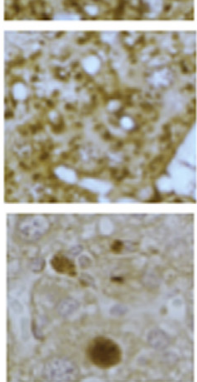

Figure 6 Protein aggregates formed in nontumor liver tissues. Immunohistochemical (IHC) serial sections of stained with antibodies against keratin-8, keratin-18, ubiquitin (using anti-FK2 antibodies that recognize poly-ubiquitin chains), and p62. A: Representative IHC staining of Brca2 DNA repair associated (Brca2) and cyclindependent kinase inhibitor $1 \mathrm{~A}$ (Cdkn1a) interacting protein (Bccip) wild-type (WT) liver tissue, demonstrating the localization of the keratins at the cytoplasmic membrane, the predominate nuclear localization of ubiquitin, and the minimum aggregate of p62 in the cytoplasm. B: Representative IHC staining of Bccip-deficient liver tissue, demonstrating the widespread accumulation of keratin and ubiquitin in the cytoplasm and scattered cytoplastic p62 aggregation in some hepatocytes. Boxed areas are shown at higher magnification in the right column ( $\mathbf{A}$ and $\mathbf{B})$. Images were obtained with $5 \times(\mathbf{A}$ and $\mathbf{B}$, left column), $20 \times$ ( $A$ and $B$, left middle column), and $40 \times$ ( $A$ and $\mathbf{B}$, right middle and right columns) objective lens. that had little gross abnormality of the livers. Eleven (five males and six females) of the 19 Bccip-deficient mice had developed ballooned hepatocytes (Supplemental Table S3). However, only one of the eight wild-type livers had this morphologic features, and another had marginal ballooning.

Cytokeratins are intermediate filament proteins normally expressed in epithelial cells, including hepatocytes. Keratin8 and keratin-18 are required for the maintenance of hepatocyte integrity, and their altered expressions were known to be related to liver diseases, including chronic hepatitis and tumorigenesis. $^{37-39}$ Positive cytoplasmic aggregates of keratin- 8 and keratin-18, ubiquitin, and p62 were often detected in ballooned hepatocytes and were considered to be the major components of the Mallory-Denk bodies associated with $\mathrm{NASH}{ }^{40-42}$ Therefore, four serial sections of nontumor liver tissues were stained for keratin-8, keratin-18, polyubiquitin, and p62. In the Bccip wild-type liver tissues (Figure 6A), the keratins were mainly present on the hepatocyte plasma membrane, which is consistent with the previous reports, ${ }^{43,44}$ and ubiquitin was mainly expressed in the nucleus of the hepatocytes. In a striking contrast, widespread hepatocyte cytoplasmic aggregates of keratin- 8 and keratin-18 were observed in most of the Bccip-deficient mice (Figure 6B). The ubiquitin immunostaining pattern was very similar to the keratin's staining in Bccip-deficient hepatocytes (Figure 6B). Interestingly, a widespread p62 aggregation was not observed in hepatocytes but only scattered p62 aggregate positive cells, although there was an increased frequency of p62 aggregate-positive cells in Bccip-deficient liver (Figure 6B). The detailed results of these IHC analyses among 19 available Bccip-deficient and 


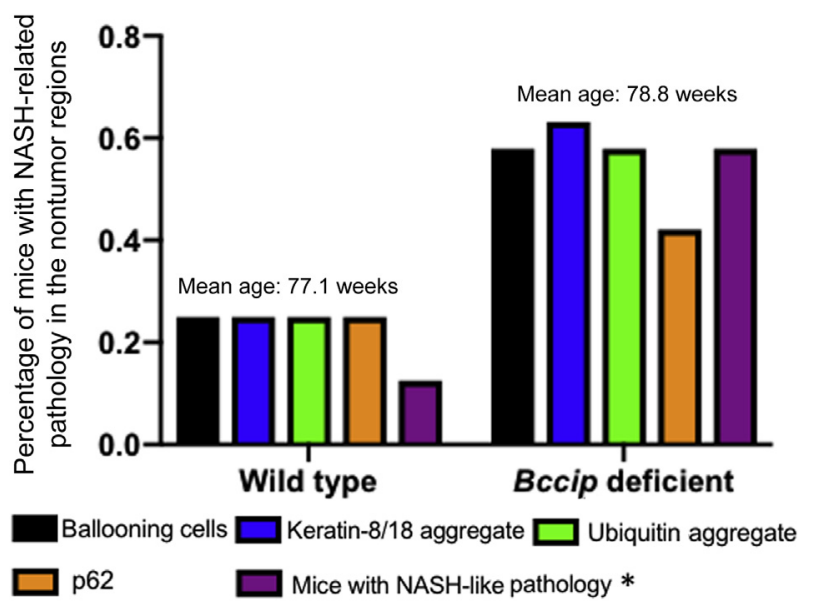

Figure 7 Summary of nonalcoholic steatohepatitis (NASH)-like pathologic findings in nontumor regions. The portion of mice displayed ballooning cells, keratin-8/18 aggregates, ubiquitin aggregates, and p62 accumulation in the nontumor liver sections. The portion of mice with NASH-like pathologic findings, defined as the presence of ballooning cells as well as protein aggregates, is also shown. See Supplemental Table S3 for details in each mouse. Asterisk indicates positive of ballooning cells and positive of cytoplasmic protein aggregates. $n=8$ wild type; $n=19$ Bccip deficient.

8 wild-type mice are listed in Supplemental Table S3 and summarized in Figure 7. Altogether, these pathologic analyses (Figures 5-7) suggested that Bccip may suppress the development of NASH, a premalignant condition that increases the risk of liver cancer.

\section{Spleen Abnormalities and Cytoplasmic Localization of HMGB1 in Bccip-Deficient Cells}

A normal spleen comprises two functionally and morphologically distinct compartments: the red pulp and white pulp. The red pulp is the blood filter and storage site for iron, erythrocytes, and platelets. The white pulp, which surrounds the central arterioles and is composed of the periarteriolar lymphoid sheath, the follicles, and the marginal zone, initiates immune responses to bloodborne antigens. ${ }^{45}$ Among the 44 Bccip-deficient mice, 12 had apparently enlarged spleens (Table 3 and Figure 8A). However, only one of the Bccip wild-type $\left(\right.$ Bccip $^{f / w t} ;$ EII $\mathrm{Cr}^{--}$) mice had an enlarged spleen. H\&E staining revealed that the enlarged spleens have lost or reduced red pulp (Figure 8A). Most cells were diffused lymphocytes, and excessive neutrophils and macrophages were also observed (Figure 8A), suggesting an inflammatory response. Although HMGB1 was accumulated in the cytoplasm in the enlarged spleens of Bccip-deficient mice (Figure 8B), the cytoplasmic location of HMGB1 was observed neither in nonenlarged spleens of Bccip-deficient mice nor in the only case of an enlarged spleen from Bccip wild-type mice (Figure 8B). The increased cytoplasmic accumulation of
HMGB1 was also observed in the liver tumor tissues of Bccip-deficient mice (Figure 8C).

HMGB1 is normally a nuclear protein; however, it can be translocated to cytoplasm and released into the intracellular environment. ${ }^{46}$ As shown in Figure 8, B and C, a common feature among the livers and spleens of Bccip-deficient mice is the excessive level of HMGB1 in the cytoplasm. It has been reported that the HMGB1 can also be released from cells after stimulation by cytokine interleukin (IL) $1 \beta .{ }^{47}$ To confirm the cytoplasmic distribution of HMGB1 observed in the liver and splenic cells of Bccip-deficient mice, BCCIP was knocked down in human skin fibroblasts. BCCIP knockdown significantly increased the cytoplasmic accumulation of HMGB1 in the IL-1 $\beta$-treated cells (Figure 8D). At the same time, Western blot using the cell extracts confirmed that there were more cytoplasmic but less nuclear HMGB1 when $B C C I P$ was knocked down and treated with IL-1 $\beta$ (Figure $8 \mathrm{E}$ ). These data suggest that of BCCIP deficiency can lead to an inflammatory response, which is accompanied with a mislocalization of HMGB1.

\section{Discussion}

This study has established a new conditional Bccip knockout mouse model. With the use of this system, homozygous Bccip deletion is found to be embryonically lethal to mice, but a Bccip mosaic and heterozygous Bccip deletion can produce viable mice. However, these mice with partial impairment of Bccip had an increased risk of spontaneous liver tumorigenesis and B-cell lymphomagenesis. These spontaneous abnormalities were accompanied with chronic inflammation and a change of HMGB1 intracellular redistribution in Bccip-deficient cells. The livers of Bccipdeficient mice display histologic changes that resemble $\mathrm{NASH}$, including the appearance of ballooning cells and keratins and ubiquitin aggregates that are normally found in Mellory-Denk bodies. The study data suggest that although a complete loss of Bccip results in lethality, a partial loss of Bccip function may trigger a chronic inflammation and increase the risks of liver tumors and B-cell lymphomas.

A previous study found that BCCIP protein expression is reduced in some HCC tissue extracts when compared with the matched normal tissues and that reduced IHC staining of BCCIP is associated with poor prognosis among 116 cases of HCC. $^{8}$ Although chronic hepatitis virus infections, alcohol consumption, and cirrhosis are historically considered the major risk factors of HCC, obesity-related fatty liver diseases are being recognized as risk factors of increasing importance. ${ }^{1,2,48-51}$ Although there are carcinogen-based liver tumor models, humanized virus infection liver models, and diet-based NAFLD mouse models, ${ }^{7}$ few spontaneous liver cancer mouse models are available to identify genetic factors that may contribute to liver cancer risk. ${ }^{3,4}$ In this model, the HCC and the NASHlike phenotypes were spontaneously developed without 
exogenous stresses. The increase in the spontaneous risks of $\mathrm{NASH}$, chronic inflammation, and liver cancers by an endogenous gene knockout represents a unique case. This study clearly found that the liver tumors had the expected homozygous or heterozygous deletion of the Bccip gene (Figure 4A), and the Bccip-deficient livers had an increased display of NASH-like histologic features (Figures 5 and 6). However, it cannot be ascertained how much the systematic inflammatory response in the Bccip-deficient mice may have contributed to the initiation and/or promotion of the tumor development. Obviously, a liver-specific knockout mouse model, such as the Alb-Cre transgenic model, ${ }^{52}$ will need to be developed to address this question.

The mechanism by which Bccip deficiency causes a NASH-like condition in the liver warrants further study. An interesting observation is that the liver tumor retained Bccip down-regulation but displayed an increased level of p62 proteins and polyubiquinated proteins. Furthermore, striking keratin and ubiquitin cytoplasmic aggregates were observed in the nontumor liver tissues of Bccip-deficient mice. These findings indicate an excessive production of misfolded proteins and/or an insufficient clearance of misfolded proteins through the autophagy or proteasome pathways. The possible role of $B C C I P$ deficiency in protein quality control and misfolded protein clearance warrants further study. In addition, Aeg-1 (Metadherin or Lyric) expression causes liver tumor associated with NAFLD and NASH, ${ }^{5,6}$ and BCCIP interacts with Aeg- $1 .{ }^{53}$ The potential role of BCCIP and AEG1 interaction in the development of liver abnormality will be investigated in the future. Another point worth mentioning is that the spontaneous inflammation and tumor formation were obtained from mice with normal diets. The HCC cases in this study were relatively small, although significant premalignant changes were observed in the Bccip-deficient livers. Thus, it would be informative to challenge the Bccip-deficient mice with liver toxins or fat diet in future studies.

A role for inflammation in tumor development is generally accepted, and an inflammatory environment appears to be an essential component of all tumors. ${ }^{54,55}$ B-cell lymphomas vary by the type of malignant cell and tumor
A
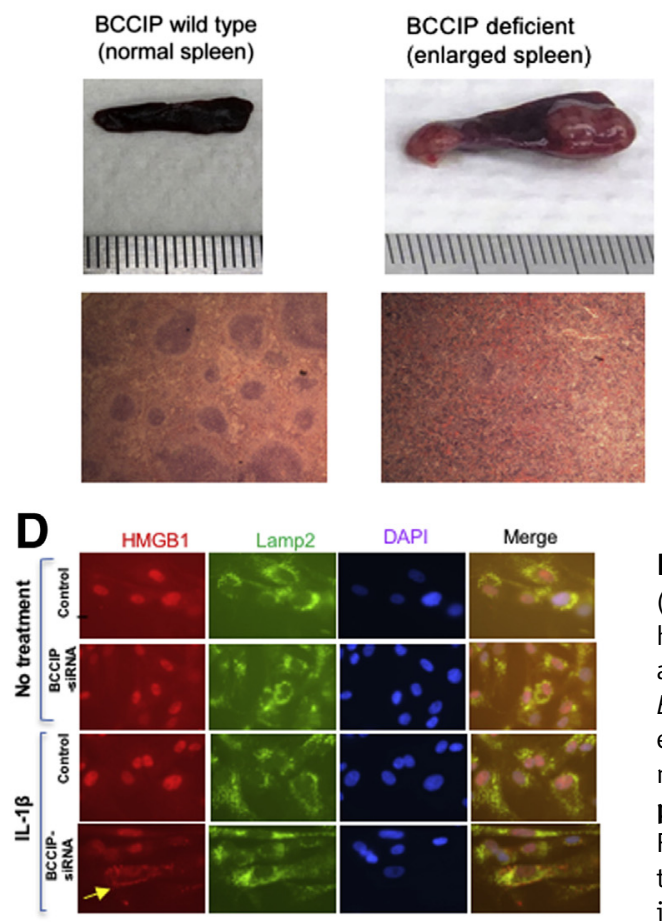

E

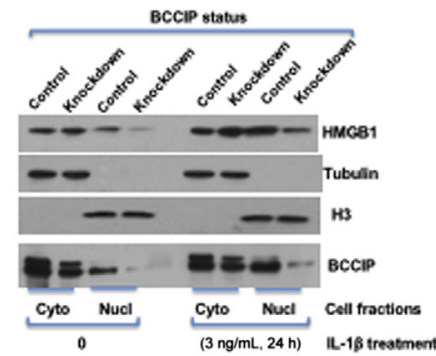

B

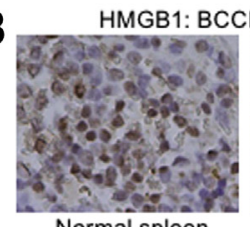

Normal spleen
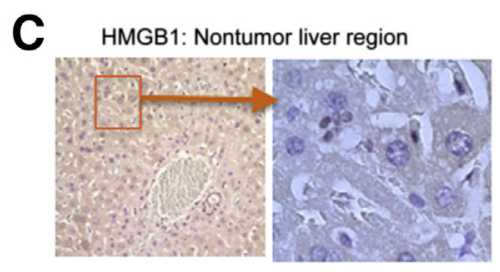

Enlarged spleen
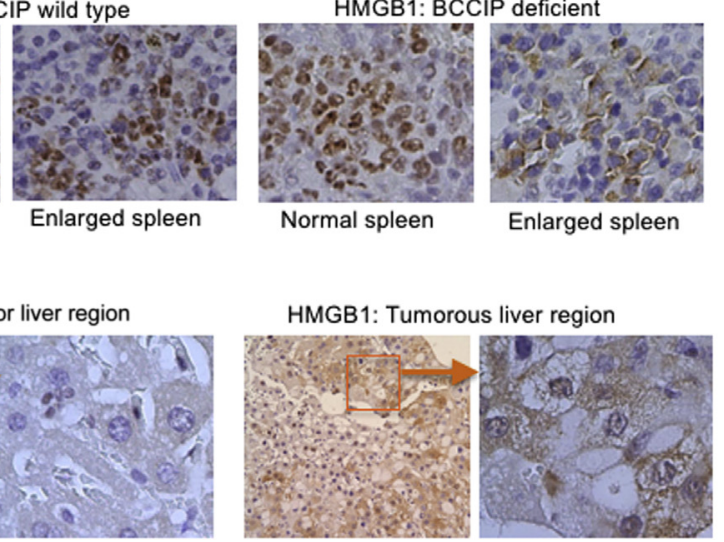

HMGB1: BCCIP deficient

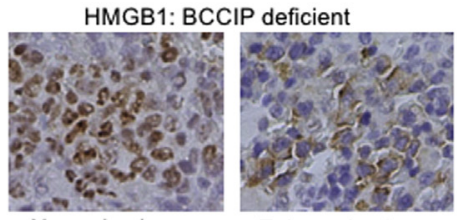

Enlarged spleen

Figure 8 Spleen abnormalities and cytoplasmic location of high-mobility group box 1 (HMGB1) protein in Brca2 DNA repair associated (Brca2) and cyclin-dependent kinase inhibitor 1A (Cdkn1a) interacting protein (Bccip)-deficient cells. A: Representative gross appearance and hematoxylin and eosin (H\&E) staining of spleens from Bccip wild-type and Bccip-deficient mice. B: Immunohistochemical (IHC) staining of HMGB1 in normal and enlarged spleen from wild-type and Bccip-deficient mice. The two left panels show the normal spleen and the only case of enlarged spleen of Bccip wild-type mice. The two right panels show the normal and enlarged spleens from Bccip-deficient mice (mosaic). C: Representative IHC for HMGB1 in liver tissue. The two left panels show the normal liver tissue. The two right panels are tumor tissue. D: Cytoplasmic localization of HMGB1 in interleukin (IL) $1 \beta$-treated Brca2 DNA repair associated (Brca2) and cyclin-dependent kinase inhibitor $1 \mathrm{~A}(\mathrm{Cdkn1a})$ interacting protein (Bccip) knockdown cells. Shown are the immunofluorescent staining of HMGB1 (red) and lysosome-associated membrane protein (Lamp2; green) in human skin fibroblasts with BCCIP knockdown. The cytoplasmic localization of HMGB1 in IL-1 $\beta$-treated BCCIP knockdown cells is indicated by an arrow. The verification of reduced protein level in BCCIP knockdown cells can be found in Figure $8 \mathrm{E}$. E: Increased cytoplasmic and reduced nuclear HMGB1 distribution in the IL-1 $\beta$-treated BCCIP knockdown cells. Cell fractionation assay was performed in BCCIP knockdown and control cells after 24 hours of IL-1 $\beta$ exposure. Tubulin and H3 were used as markers for cytosolic and nuclear fractions, respectively. The level of BCCIP knockdown was verified in both cytoplasmic (Cyto) and nuclear (NuCl) fractions (bottom panel). Original magnification: $\times 10$ (A, and C, two left panels); $\times 40$ (B, and C, two right panels, and D). 
location. It is known that an inflammatory microenvironment has a causal role in the development of B-cell lymphomas. ${ }^{56}$ Various genetically engineered mouse models have been developed to understand how B-cell lymphomas arise. ${ }^{57}$ Some of the genetically engineered mouse models reproduced the inflammatory context of B-cell lymphoma development, but others do not. Our model found a chronic inflammatory response in Bccip-deficient mice, which accompanied by B-cell lymphoma. Although all cases with lymphoma have inflammatory phenotypes, in some cases enlarged spleen and inflammatory response was observed but with no clear development of lymphoma in the tissues examined. This finding is agrees with the idea that inflammation may precede lymphomagenesis.

HMGB1 plays a role in liver disease and $\mathrm{HCC} .^{58}$ As a damage-associated molecular pattern molecule, HMGB1 is known to stimulate inflammatory response by interacting with Toll-like receptor 4 and activating cytokine release by macrophages. ${ }^{59,60}$ Furthermore, the extracellular HMGB1 secreted by the activated macrophages and monocytes is believed to be a mediator of inflammation. ${ }^{60,61}$ This study found that HMGB1 accumulates in cytoplasm in the enlarged spleens and liver tumors in Bccip heterozygous and mosaic mice (Figure 8, B and C). Although it remains a question of whether there is a cause-consequence relationship between BCCIP loss and inflammation, even a partial knockdown of $B C C I P$ in human cells could directly cause the translocation of HMGB1 into the cytoplasm when the cells were treated with IL-1 $\beta$ (Figure 8, D and E). These data implicate that BCCIP itself may suppress inflammatory response by restricting HMGB1 in the nucleus after IL-1 $\beta$ stimulation.

In summary, we have established a new Bccip knockout mouse model. With the use of this model, a partial Bccip defect was found to be a risk factor for spontaneous inflammation and non-alcohol-associated liver diseases and B-lymphoma development.

\section{Author Contributions}

Z.S. conceived and supervised the study and acquired funds; H.L., C.Y., X.F., J.L., and M.B. performed experiments; B.X. and C.L. provided resources; H.L. and Z.S. wrote the manuscript; and B.X., C.L., and Z.S. reviewed and edited the manuscript.

\section{Supplemental Data}

Supplemental material for this article can be found at http://doi.org/10.1016/j.ajpath.2020.01.020.

\section{References}

1. Younossi ZM, Loomba R, Anstee QM, Rinella ME, Bugianesi E, Marchesini G, Neuschwander-Tetri BA, Serfaty L, Negro F, Caldwell SH, Ratziu V, Corey KE, Friedman SL, Abdelmalek MF,
Harrison SA, Sanyal AJ, Lavine JE, Mathurin P, Charlton MR, Goodman ZD, Chalasani NP, Kowdley KV, George J, Lindor K: Diagnostic modalities for non-alcoholic fatty liver disease (NAFLD), non-alcoholic steatohepatitis (NASH) and associated fibrosis. Hepatology 2017, 68:349-360

2. Sun B, Karin M: Obesity, inflammation, and liver cancer. J Hepatol 2012, 56:704-713

3. Bakiri L, Wagner EF: Mouse models for liver cancer. Mol Oncol 2013, 7:206-223

4. Nakamura A, Terauchi Y: Lessons from mouse models of high-fat diet-induced NAFLD. Int J Mol Sci 2013, 14:21240-21257

5. Srivastava J, Siddiq A, Emdad L, Santhekadur PK, Chen D, Gredler R, Shen XN, Robertson CL, Dumur CI, Hylemon PB, Mukhopadhyay ND, Bhere D, Shah K, Ahmad R, Giashuddin S, Stafflinger J, Subler MA, Windle JJ, Fisher PB, Sarkar D: Astrocyte elevated gene-1 promotes hepatocarcinogenesis: novel insights from a mouse model. Hepatology 2012, 56:1782-1791

6. Yoo BK, Emdad L, Su ZZ, Villanueva A, Chiang DY, Mukhopadhyay ND, Mills AS, Waxman S, Fisher RA, Llovet JM, Fisher PB, Sarkar D: Astrocyte elevated gene-1 regulates hepatocellular carcinoma development and progression. J Clin Invest 2009 119:465-477

7. Denk H, Abuja PM, Zatloukal K: Animal models of NAFLD from the pathologist's point of view. Biochim Biophys Acta Mol Basis Dis 2019, 1865:929-942

8. Lin Z, Hu B, Ni W, Mao X, Zhou H, Lv J, Yin B, Shen Z, Wu M, Ding W, Xiao M, Ni R: Expression pattern of BCCIP in hepatocellular carcinoma is correlated with poor prognosis and enhanced cell proliferation. Tumour Biol 2016, 37:16305-16315

9. Liu J, Yuan Y, Huan J, Shen Z: Inhibition of breast and brain cancer cell growth by BCCIPalpha, an evolutionarily conserved nuclear protein that interacts with BRCA2. Oncogene 2001, 20: $336-345$

10. Ono T, Kitaura H, Ugai H, Murata T, Yokoyama KK, IguchiAriga SM, Ariga H: TOK-1, a novel p21Cip1-binding protein that cooperatively enhances p21-dependent inhibitory activity toward CDK2 kinase. J Biol Chem 2000, 275:31145-31154

11. Lu H, Guo X, Meng X, Liu J, Allen C, Wray J, Nickoloff JA, Shen Z: The BRCA2-interacting protein BCCIP functions in RAD51 and BRCA2 focus formation and homologous recombinational repair. Mol Cell Biol 2005, 25:1949-1957

12. Lu H, Huang YY, Mehrotra S, Droz-Rosario R, Liu J, Bhaumik M, White E, Shen Z: Essential roles of BCCIP in mouse embryonic development and structural stability of chromosomes. PLoS Genet 2011, 7:e1002291

13. Lu H, Yue J, Meng X, Nickoloff JA, Shen Z: BCCIP regulates homologous recombination by distinct domains and suppresses spontaneous DNA damage. Nucleic Acids Res 2007, 35:7160-7170

14. Kelso AA, Goodson SD, Watts LE, Ledford LL, Waldvogel SM, Diehl JN, Shah SB, Say AF, White JD, Sehorn MG: The beta-isoform of BCCIP promotes ADP release from the RAD51 presynaptic filament and enhances homologous DNA pairing. Nucleic Acids Res 2017, 45:711-725

15. Meng X, Yue J, Liu Z, Shen Z: Abrogation of the transactivation activity of p53 by BCCIP down-regulation. J Biol Chem 2007, 282: $1570-1576$

16. Meng X, Fan J, Shen Z: Roles of BCCIP in chromosome stability and cytokinesis. Oncogene 2007, 26:6253-6260

17. Fan J, Wray J, Meng X, Shen Z: BCCIP is required for the nuclear localization of the p21 protein. Cell Cycle 2009, 8:3019-3024

18. Huhn SC, Liu J, Ye C, Lu H, Jiang X, Feng X, Ganesan S, White E, Shen Z: Regulation of spindle integrity and mitotic fidelity by BCCIP. Oncogene 2017, 36:4750-4766

19. Wyler E, Wandrey F, Badertscher L, Montellese C, Alper D, Kutay U: The beta-isoform of the BRCA2 and CDKN1A(p21)interacting protein (BCCIP) stabilizes nuclear RPL23/uL14. FEBS Lett 2014, 588:3685-3691 
20. Ting YH, Lu TJ, Johnson AW, Shie JT, Chen BR, Kumar SS, Lo KY: $\mathrm{Bcp} 1$ is the nuclear chaperone of Rpl23 in saccharomyces cerevisiae. J Biol Chem 2017, 292:585-596

21. Ba Q, Li X, Huang C, Li J, Fu Y, Chen P, Duan J, Hao M, Zhang Y, Li J, Sun C, Ying H, Song H, Zhang R, Shen Z, Wang H: BCCIPbeta modulates the ribosomal and extraribosomal function of S7 through a direct interaction. J Mol Cell Biol 2017, 9:209-219

22. Mao N, Zhou Q, Kojic M, Perez-Martin J, Holloman WK: Ortholog of BRCA2-interacting protein BCCIP controls morphogenetic responses during DNA replication stress in Ustilago maydis. DNA Repair (Amst) 2007, 6:1651-1660

23. Audhya A, Emr SD: Regulation of PI4,5P2 synthesis by nuclearcytoplasmic shuttling of the Mss4 lipid kinase. EMBO J 2003, 22: 4223-4236

24. Meng X, Liu J, Shen Z: Genomic structure of the human BCCIP gene and its expression in cancer. Gene 2003, 302:139-146

25. Liu J, Lu H, Ohgaki H, Merlo A, Shen Z: Alterations of BCCIP, a BRCA2 interacting protein, in astrocytomas. BMC Cancer 2009, 9: 268

26. Rewari A, Lu H, Parikh R, Yang Q, Shen Z, Haffty BG: BCCIP as a prognostic marker for radiotherapy of laryngeal cancer. Radiother Oncol 2009, 90:183-188

27. Liu X, Cao L, Ni J, Liu N, Zhao X, Wang Y, Zhu L, Wang L, Wang J, Yue Y, Cai Y, Jin J: Differential BCCIP gene expression in primary human ovarian cancer, renal cell carcinoma and colorectal cancer tissues. Int J Oncol 2013, 43:1925-1934

28. Droz-Rosario R, Lu H, Liu J, Liu NA, Ganesan S, Xia B, Haffty BG, Shen Z: Roles of BCCIP deficiency in mammary tumorigenesis. Breast Cancer Res 2017, 19:115

29. Huang YY, Dai L, Gaines D, Droz-Rosario R, Lu H, Liu J, Shen Z: BCCIP suppresses tumor initiation but is required for tumor progression. Cancer Res 2013, 73:7122-7133

30. Huang YY, Lu H, Liu S, Droz-Rosario R, Shen Z: Requirement of mouse BCCIP for neural development and progenitor proliferation. PLoS One 2012, 7:e30638

31. Didier C, Merdes A, Gairin JE, Jabrane-Ferrat N: Inhibition of proteasome activity impairs centrosome-dependent microtubule nucleation and organization. Mol Biol Cell 2008, 19:1220-1229

32. Bartlett BJ, Isakson P, Lewerenz J, Sanchez H, Kotzebue RW, Cumming RC, Harris GL, Nezis IP, Schubert DR, Simonsen A, Finley KD: p62, Ref(2)P and ubiquitinated proteins are conserved markers of neuronal aging, aggregate formation and progressive autophagic defects. Autophagy 2011, 7:572-583

33. Zhong L, Martinez-Pastor B, Silberman DM, Sebastian C, Mostoslavsky R: Assaying chromatin sirtuins. Methods Mol Biol 2013, 1077:149-163

34. Coston WM, Loera S, Lau SK, Ishizawa S, Jiang Z, Wu CL, Yen Y, Weiss LM, Chu PG: Distinction of hepatocellular carcinoma from benign hepatic mimickers using Glypican-3 and CD34 immunohistochemistry. Am J Surg Pathol 2008, 32:433-444

35. Enan ET, El-Hawary AK, El-Tantawy DA, Abu-Hashim MM, Helal NM: Diagnostic role of glypican 3 and CD34 for differentiating hepatocellular carcinoma from nonmalignant hepatocellular lesions. Ann Diagn Pathol 2013, 17:490-493

36. Tatrai P, Somoracz A, Batmunkh E, Schirmacher P, Kiss A, Schaff Z, Nagy P, Kovalszky I: Agrin and CD34 immunohistochemistry for the discrimination of benign versus malignant hepatocellular lesions. Am J Surg Pathol 2009, 33:874-885

37. Liu YH, Cheng CC, Ho CC, Chao WT, Pei RJ, Hsu YH, Yeh KT, Ho LC, Tsai MC, Lai YS: Degradation of plectin with modulation of cytokeratin 18 in human liver cells during staurosporine-induced apoptosis. In Vivo 2008, 22:543-548

38. Omary MB, Ku NO: Intermediate filament proteins of the liver: emerging disease association and functions. Hepatology 1997, 25:1043-1048

39. Galarneau L, Loranger A, Gilbert S, Marceau N: Keratins modulate hepatic cell adhesion, size and G1/S transition. Exp Cell Res 2007, 313:179-194
40. Golob-Schwarzl N, Bettermann K, Mehta AK, Kessler SM, Unterluggauer J, Krassnig S, Kojima K, Chen X, Hoshida Y, Bardeesy NM, Muller H, Svendova V, Schimek MG, Diwoky C, Lipfert A, Mahajan V, Stumptner C, Thuringer A, Frohlich LF, Stojakovic T, Nilsson KPR, Kolbe T, Rulicke T, Magin TM, Strnad P, Kiemer AK, Moriggl R, Haybaeck J: High keratin 8/18 ratio predicts aggressive hepatocellular cancer phenotype. Transl Oncol 2019, 12:256-268

41. Zatloukal K, French SW, Stumptner C, Strnad P, Harada M, Toivola DM, Cadrin M, Omary MB: From Mallory to Mallory-Denk bodies: what, how and why? Exp Cell Res 2007, 313:2033-2049

42. Strnad P, Zatloukal K, Stumptner C, Kulaksiz H, Denk H: MalloryDenk-bodies: lessons from keratin-containing hepatic inclusion bodies. Biochim Biophys Acta 2008, 1782:764-774

43. Wells MJ, Hatton MW, Hewlett B, Podor TJ, Sheffield WP, Blajchman MA: Cytokeratin 18 is expressed on the hepatocyte plasma membrane surface and interacts with thrombin-antithrombin complexes. J Biol Chem 1997, 272:28574-28581

44. Hembrough TA, Li L, Gonias SL: Cell-surface cytokeratin 8 is the major plasminogen receptor on breast cancer cells and is required for the accelerated activation of cell-associated plasminogen by tissuetype plasminogen activator. J Biol Chem 1996, 271:25684-25691

45. Cesta MF: Normal structure, function, and histology of the spleen. Toxicol Pathol 2006, 34:455-465

46. Gauley J, Pisetsky DS: The translocation of HMGB1 during cell activation and cell death. Autoimmunity 2009, 42:299-301

47. Hayakawa K, Arai K, Lo EH: Role of ERK map kinase and CRM1 in IL-1beta-stimulated release of HMGB1 from cortical astrocytes. Glia 2010, 58:1007-1015

48. Serfaty L: Management of patients with non-alcoholic steatohepatitis (NASH) in real life. Liver Int 2018, 38 Suppl 1:52-55

49. Seko Y, Yamaguchi K, Itoh Y: The genetic backgrounds in nonalcoholic fatty liver disease. Clin J Gastroenterol 2018, 11:97-102

50. Marcellin P, Kutala BK: Liver diseases: a major, neglected global public health problem requiring urgent actions and large-scale screening. Liver Int 2018, 38 Suppl 1:2-6

51. Ibrahim SH, Hirsova P, Gores GJ: Non-alcoholic steatohepatitis pathogenesis: sublethal hepatocyte injury as a driver of liver inflammation. Gut 2018, 67:963-972

52. Weisend CM, Kundert JA, Suvorova ES, Prigge JR, Schmidt EE: Cre activity in fetal albcre mouse hepatocytes: utility for developmental studies. Genesis 2009, 47:789-792

53. Ash SC, Yang DQ, Britt DE: LYRIC/AEG-1 overexpression modulates BCCIPalpha protein levels in prostate tumor cells. Biochem Biophys Res Commun 2008, 371:333-338

54. DiDonato JA, Mercurio F, Karin M: NF-kappaB and the link between inflammation and cancer. Immunol Rev 2012, 246:379-400

55. Mantovani A, Allavena P, Sica A, Balkwill F: Cancer-related inflammation. Nature 2008, 454:436-444

56. Carbone A, Tripodo C, Carlo-Stella C, Santoro A, Gloghini A: The role of inflammation in lymphoma. Adv Exp Med Biol 2014, 816:315-333

57. Donnou S, Galand C, Touitou V, Sautes-Fridman C, Fabry Z, Fisson S: Murine models of B-cell lymphomas: promising tools for designing cancer therapies. Adv Hematol 2012, 2012:701704

58. Chen R, Hou W, Zhang Q, Kang R, Fan XG, Tang D: Emerging role of high-mobility group box 1 (HMGB1) in liver diseases. Mol Med 2013, 19:357-366

59. Yang H, Tracey KJ: Targeting HMGB1 in inflammation. Biochim Biophys Acta 2010, 1799:149-156

60. Yang H, Hreggvidsdottir HS, Palmblad K, Wang H, Ochani M, Li J, Lu B, Chavan S, Rosas-Ballina M, Al-Abed Y, Akira S, Bierhaus A, Erlandsson-Harris H, Andersson U, Tracey KJ: A critical cysteine is required for HMGB 1 binding to Toll-like receptor 4 and activation of macrophage cytokine release. Proc Natl Acad Sci U S A 2010, 107 : 11942-11947

61. Klune JR, Dhupar R, Cardinal J, Billiar TR, Tsung A: HMGB1: endogenous danger signaling. Mol Med 2008, 14:476-484 